\title{
RHETORICAL MOVES AND LINGUISTIC FEATURES OF JOURNAL ARTICLE ABSTRACTS BY POSTGRADUATE STUDENTS, NATIONAL AND INTERNATIONAL AUTHORS IN APPLIED LINGUISTICS
}

\author{
Rosy Putri Andika \\ Safnil \\ Alamsyah Harahap \\ University of Bengkulu \\ rosyputriandika@gmail.com
}

\begin{abstract}
The abstract has become the first part that will be read by readers in a research article. Some important aspects in the abstract are move structure and linguistic features. This study examines the rhetorical moves and linguistic features of English research article abstract written by three groups of authors in Applied Linguistics. The research design was mixed method design combining quantitative and qualitative method with the corpus of this study consisted of 60 abstracts by postgraduate students, national and international authors found in RA abstracts. The results show that the common moves by three groups of authors have only three moves (i.e purpose, method, and results). The common linguistic features used by three groups of authors are active voice, present tense, and simple sentence. By comparing the three groups of abstracts the differences are found in the postgraduate students authors. They were used move 1 (Background/ introduction/ situation) fewer than national and international authors. Furthur the postgraduate students used past tense more dominant than present tense and using hedges is more frequently than national and international authors. This study concludes that in writing RA abstracts a writer should adjust the commonly used rules the abstract especially in using 5 moves in the abstracts.
\end{abstract}

Key Words: Abstract, Rhetorical Move, Applied Linguistics

\section{INTRODUCTION}

An abstract is the first part that will be read in the publication journal, research article, thesis, and so on. The readers can overview the content of a journal by reading an abstract. Submitting an abstract is an important thing even in national or international journal. The objective can be more detail seen by reading the abstract. Abstract is beneficial for the reader to identify the keywords that will make it easier for exploring the research.
The moves of abstracts are to extend the purpose in research article. Writing abstract becomes an obligation in journal, research article, and thesis. Swales and Feak (2009) investigated that the number of "rhetorical moves" (or communicative stages) in abstracts can be found in various fields and in various languages. Most researchers identify a potential total of five moves in the rhetorical structure of abstract. In the other words, abstract can identify a whole content of a study and such an option for the 
reader to continue to read the study or not.

Although an abstract is very important on the research article, writing abstract is not easy for students, novice, and new writers. According to Safnil (2014) writing an abstract for RA (Research Article) is not only difficult for university students; it is also hard for lecturer and novice writers. It might be different problems for different group of writers ( i.e. Postgraduate Students, national and international authors). An increasingly important area in such research is the study of thesis writing at the postgraduate level, with much attention paid to theses written in English as a second or foreign language (Ren and $\mathrm{Li}$ : 2011). Other problems of writing abstract in English by non-native are the right choice of tenses and sentence patterns.

Based on the explanation above, one of the main problems experienced by research article author is writing abstract. Choosing the right tenses and sentence patterns become the problems in writing abstract. However, the comparative study on various groups of writers still rarely done especially is research article abstract in Applied Linguistics. This is the rational of this study that is to investigate the similarities and differences on move structure of abstract written by three groups of authors they are postgraduate students, national and international authors.

Based on the background of this research, the problems as followed, writing abstract is difficult not only for the novice or new writer but also postgraduate students, national and international authors. The problem in writing abstract still found in move structural, tenses, and sentence patterns, and finally analyzing English abstract in Indonesia is still rarely done. Many studies have analyzed abstract in different aspects. Ren and Li (2011: 162) compared the study on the rhetorical moves of abstracts in published research articles and master's foreign language theses. They found that five basic rhetorical moves in developing abstracts were commonly found in the abstracts written by both experts and student writers, experts tend to be more selective in their use of the moves to best promote their papers, while student writers tend to include all the moves to be more informative of the content and structure of their theses. Some student writers even include "limitation" in their abstracts without mentioning the strength, which might undermine the value of their work. This is in contrast to expert writers' effort in promoting their paper in their abstract by including the "conclusion" move more often. Students' lengthy "introduction" move and over brief "product" move, in contrast to expert writers' balanced use of these two moves, reveals their insecurity as novice writers. Students' repetition in their abstracts indicates their unawareness of the value of space in academic writing.

The other research analyzed the comparison in different grade of ability (San and Tan, 2012: 40). They compared study the rhetorical moves in abstracts of students' term papers 
and published articles in the field of Computer and Communications Systems Engineering. They found that Move 1 and Move 2 were seen to be the obligatory moves for the two groups of writers although the total occurrences of both moves were higher in the expert abstracts. Move 3 which was seen as optional for the expert writers was however, seen as obligatory for the novice writers. For Move 4, although both groups of the writers regarded the move as optional, the novice writers had less tendency of using the move than the expert writers. However, Move 5 which appeared to be optional too for both groups of writers was seen to be used more by the novice writers in the abstract writing. In other words, the expert and novice writers were seen to take Move 1 and Move 2 as the obligatory moves but for Move 3, Move 4 and Move 5 the writers tended to have different preferences of using the moves.

Almost the same issue Tseng (2011: 27) examined 90 research article abstract in three linguistics journals from two dimensions, there are the move structure and the second is the verb tense of each move. The analysis included the distribution of the five moves, the move structures, and the distribution of the opening and closing moves of abstracts. He found that the abstracts analyzed tended to take a four- move structure instead of five- move one as proposed in literature. He was also found that there were some variations between the abstract written by native speakers and nonnative speakers of English.

Can, et al (2016) studied fifty research articles were randomly selected from the ESP journal, the abstracts were taken from recent issues published between 2011 and 2013 preferred to reflect current writing practices. They found that authors discuss results, purpose, and methodology in their abstracts more than implications of the findings or background information. They said the authors are well aware of the fact that they need to use the allowed space economically, then the background information about the topic is the first to be omitted by writers in Applied Linguistics, and thus it seems to be the only move in the optional category, being disregarded in more than half of the sampled abstracts.

In addition, an abstract has also been analyzed in any disciplines. Some studies have conducted the research in Applied Linguistic. Safnil (2014), investigated thirty abstracts in three disciplines (i.e. Humanity economics, management, and education) written in English by Indonesian writers. Firstly, he found that the major of RA abstracts written in English by Indonesian academics in the corpus of this study have only three moves (i.e. Purpose, method, and results) Second, the English abstracts found in the data of this study are mostly written in active sentence using present tense except for move 3 (Methods) in which half of them are written in past tense that - complement sentences are mostly found in move- 4 (results and finding).

Based on the previous studies above the comparative studies conducted in term papers and thesis students. However, this study is the comparative study on various groups 
of writers still rarely done especially is research article abstract in Applied Linguistics. This study will be analyzed five moves patterns and linguistic features in research article abstact written by three group of writers such as postgraduate students, national authors, and international authors.

\section{METHODOLOGY}

This research is conducted by using mixed method to answer three questions, namely the rhetorical moves and linguistic features in RA abstracts by postgraduate students, national authors, and international authors in Applied Linguistic. According to Creswell and Plano (2007) mentions that side steps the issue of paradigms, but characterizes mixed methods research as having a set of guiding philosophical assumptions and a method where a qualitative and quantitative were mixed at some point in the study. The qualitative method used in collecting the data to compare by three groups of writers (i.e Postgraduate Students, national authors, and International Authors), while the quantitative method used in analyzing the research article abstracts by different group of writers in Applied Linguistics.

The corpus of this study consisted of sixty RA abstracts in applied linguistics written by different group of authors (i.e postgraduate students, national authors, and international authors) they were; twenty journals were randomly selected by postgraduate students (RA abstracts) in applied linguistics, twenty RA abstracts by national authors (teacher/ lecturer) in applied linguistics, and twenty RA abstracts were from international authors in applied linguistics.

The postgraduate students used research article abstracts in Journal of English Language and Literature Education (JOALL) by English education department at University of Bengkulu. Research article abstracts by national authors was taken in TEFLIN Journal's website, international authors' abstract was taken from some website such as International Journal of English Studies (IJES) and ASIA EFL Journal Professional Articles. Table 1 presents the distribution of abstracts as the corpus of the study.

The instrument of this study was checklist containing of five move patterns and checklist containing of linguistic features. The moves used by Swales (2009) with five moves such as Move 1) Background/Introduction/ Situation, Move 2) Present research / Purposes, Move 3), Methods/ Materials/ Subject/ Procedures, Move 4), Results/ Finding and Move 5), Discussion/ Conclusion/ Implication/ Recommendation.

In addition, checklist for linguistic feature contained such as voice (passive and active voice), tenses (present and past tense), type of sentence (simple and complex sentence), and metadiscourse devices (hedges, attitudinal stance, and selfreference words) modified in Zhang, et al (2012). 
Table 1: Frequency of Moves in

English Research Article Abstracts

\begin{tabular}{|c|c|c|c|c|c|c|}
\hline \multirow{2}{*}{ No } & \multirow{2}{*}{ Moves } & \multicolumn{5}{|c|}{ Abstract written by three groups of authors } \\
\cline { 3 - 6 } & & PS & NA & IA & Total & \multirow{2}{*}{$\%$} \\
\cline { 3 - 6 } & & $\mathrm{n}=20$ & $\mathrm{n}=20$ & $\mathrm{n}=20$ & $\mathrm{~N}=60$ & \\
\hline 1. & Move 1 & 4 & 12 & 9 & 25 & $41,7 \%$ \\
\hline 2. & Move 2 & 20 & 16 & 19 & 55 & $91,7 \%$ \\
\hline 3. & Move 3 & 20 & 16 & 18 & 54 & $90 \%$ \\
\hline 4. & Move 4 & 20 & 18 & 19 & 57 & $95 \%$ \\
\hline 5. & Move 5 & 13 & 13 & 11 & 37 & $61,7 \%$ \\
\hline
\end{tabular}

Because of the analysis of moves and linguistic feature involved subjective judgment. A Co- rater was asked to analyze sample of abstract in order to ensure the validity of text analysis. The Co- rater was a postgraduate student in English department at education faculty, Universitas Sebelas Maret. First, the co- rater has been told how to identify the abstracts in structure move and linguistic features following the analysis procedure already described. The rater has been given 15 out of 60 abstracts (20\%) from the corpus of this study. In this research, the result of the researcher and co- rater was compared.

\section{RESULTS AND DISCUSSION}

This chapter presents the results and finding of this study based on analyzed the English abstracts written by three groups of authors in Applied Linguistics. The analyses also compared with corater, and the result discussed as follows.
Sixty English RA abstracts in different groups of authors have been analyzed in this research, they were written by postgraduate students (PS), national authors (NA), and international authors (IA). The results as displayed in the following table.

\section{Note:}

$P S=$ Postgraduate Students

$N A=$ National Authors

$I A=$ International Authors

$N=$ Total Abstracts

As shown in Table 3, the most dominant move found in the abstracts written by three groups of authors are move 2 (Present research/ Purposes) used by 55 authors (91,7\%), move 3 (Methods/ Materials/ Subject/ Procedures) used by 54 authors (90\%). and move 4 (Results/ Finding) used by 57 authors (95\%). The example of abstract with three dominant moves is as follow:

Example 1:

\{M2\} (S-1) This research was aimed to find out the students', lecturers', and experts' perspective toward the quality of the English course book for nursing department students. $\{\mathbf{M} 3\}$ 
(S-2)This research was an evaluative study. (S-3)The participants of this research were 3 experts, 3 lecturers and 80 nursing students. (S4)The instrument of this research was an evaluation checklist based on McDonough and Shaw's criteria. $\{\mathbf{M} 4\} \quad(\mathbf{S}-5)$ The findings of the research were (1) over eighty percent participants agreed that syllabus fulfills the criteria for quality a nursing course book; (2) over eighty percent participants agreed that the content area fulfills the criteria for quality a nursing course book; (3) over ninety percent participants agreed that layout and physical appearance fulfills the criteria for quality a nursing course book; (4) over eighty percent participants agreed that practicality fulfills the criteria for quality a nursing course book; (5) over eighty percent participants agreed that language use fulfills the criteria for quality a nursing course book. (PS-6)

The example above shows that the first sentence is chategorized as move 2 which contains the purpose/ present of the study, because the lexicon 'aimed' indicates that the author explains the present study. In the example 1 , the sentence 2 to 4 are chategorized as move 3 , because the lexicon '...evaluative study', 'The participants...', 'The instrument...' indicate that they explained the method, subjects, and instrument of the study. Afterwards, In the sentence 5 the author defined the results/ findings of the research. It can be implied by the use of words ' the findings of the research...' that can be chategorized as move 4 . Thus from explanation above this abstract have in three moves (move 2, move 3 , and move 4).

Table 3 above also shows that move 5 (Discussion/ Conclusion/ implication/ recommmendation) used by 37 authors $(61,7 \%)$ in writing abstracts. Here is the example of move 5 :

Example 2:

$\{$ M5\}(S-9) '....Finally the study suggested implications and recommendations for additional studies within the Indonesian context.' (NA 11)

In example 2, move 5 can be found in sentence 9 of the abstract. It can be identidfied by the use specific lexicon of ' implication', and 'recommendation' that indicate the author providing implication and recommendation of the research.

The used of move 1 (Background, introduction, situation) is also shown in Table 3. Move 1 reaches the samllest frequency and used by only 25 authors $(41,7 \%)$. The example of move 1 in an abstarct is as follow:

Example 3:

\{M1\}(S-1)

'ASEAN

Economic Community (AEC) has become a popular issue. However, there are many obstacles in joining AEC. (S- 
2) One of them is English for communication.

Unfortunately, business English letters as the media for communication in business are not taught at schools. (S-4) In fact, in this free trade era high school leavers are enhanced for being businessmen that need communications for business...' (IA-3)

In the example above, sentence 1 to 4 are chategorized as move 1 , because those sentences defined the situation/ background/ introduction of the research. It implies that the author tried to introduce the issue by describing phenomena that happened in AEC.

In this study there are linguistic features that has been analyzed, such as Voice (active and passive voice), Tenses (past and present tense), Sentence type (Simple and Complex sentence), and Metadiscourse devices (Hedges, Attitudinal Stance, and SelfReference words). The finding shown are as following description.

The results of voice features analysis in RA abstracts written by three groups of authors (i.e Postgraduate students, national and international authors) The total usage of active voice is 153 times $(69,2 \%)$ while the passive voice is just 68 times $(29,8 \%)$ in the moves of abstracts. It means that the dominant use. The example of active voice in the abstracts as follow:

Example 4:
(S-6) 'This study aims at knowing the common stages of business English letters via email, whether the writers and the addressees understand the letters, and the strategies used in the letters...'(IA-3) (M-2)

In the example above, the sentence is chategorized as active voice. The possible reason is the sentence In RA abstract commonly using a noun phrase as the subject of the sentence, such as this research, this study, the paper, etc. This results in line with Zhang et al (2012) who found that the active voice was common in all the five moves of the abstracts.

Eventhough active voice as the highest fequency, but passive voice also used in the abstracts. The example of passive voice as below:

Example 5:

(S-10) '....The students'
perception indicates the
developed materials were
oriented to students' need,
interesting and proven to be
useful to solve the problem of
lack of materials in English
for Accounting. (PS-20) (M5)

As shown in the example above, the authors used passive voice as an expression of move 5 in the abstract. This study has analyzed that the use of passive voice exists in all moves of abstracts. It seems that the authors used active or passive voice as an optional features in the moves of abstracts.

Other linguistic features analyzed in English RA abstracts are 
tenses (present tense and past tenses). The total sentence with present tense is 112 three groups of authors, this study indicates that postgraduate students obtain different results. The authors of times $(49,1 \%)$ while the past tense is 97 times $(42,5 \%)$ in the moves of abstracts. It implies that the dominant usage of tenses features is present tense. By comparing the PS groups used past tense more dominant than present tense. It might be the PS groups supposed that the research had been done, so they tend to use past tense than present tense. The example of present tense as dominant usage is as follow:

Example 6:

(S-1) 'This paper identifies challenges that English as a foreign language (EFL) novice teachers in Indonesia may face in developing a professional identity, which, in this paper, refers to becoming a practitioner of cooperative learning...' (NA9) (M-2)

In the example 6, the auhor used present tense in move 2 to define the purpose of the research by using of present verb 'identifies'. This study has analyzed that the present tense is common used in the introduction, purposes, and conclusion.

Example 7:

(S-2) '...The method applied in this research was descriptive method. Data collection techniques used observation check list. There were three textbooks observed. The aspects that were observed consisted of content, presentation, language, and graphic...' (PS-11) (M-3)

The example above shows that the author used past tense to explain the method/ materials/ subject, and procedure of the research. It can be seen by using of past participle such as 'applied', 'used', and 'observed'.

The type of sentence in English RA abstacts also have analyzed in this study. As can be seen in the table 6, the most dominant type of sentence is simple sentence. It indicates that the simple sentence is understanable in RA abstracts. Although the simple sentence as dominant usage, the complex sentence also exists in the moves of abstarcts. The example of simple sentence as below:

Example 8:

(S-1) This article reports a study on teachers' use of interaction strategies in English Language Teaching (ELT) in lower secondary level of education...' (NA-1) (M-1)

In example 8 above abstracts use simple sentence, because in the sentence have main verb to express the moves of abstracts.

Example 9:

(S-9) '....Nevertheless, the study provides English language teachers of situations where anxiety is 
most likely triggered in a NNS-NNS communication setting. (IA-9) (M-5)

In example 9, the author used complex sentence as the conclusion in move 5 of abstract. It can be seen by the use of lexicon 'nevertheless' as a mark of complex sentence. Actually, simple and complex sentences are choice to the authors as an expression in the moves of abstracts. The important point is simple or complex sentence used in moves to make the abstracts understandable for the readers.

Metadiscourse devices consisted of hedges, attitudinal stance, and self- reference in RA abstracts written by three groups of authors.

Table 7 concludes that the authors in usage of hedges, attitudinal stance, and self- reference words are just a view. The total usage of hedges is 14 times $(6,8 \%)$, attitudinal stance is only one time $(0,4 \%)$, and self- reference words is 10 times $(4,6 \%)$ in the abstract. The example of hedges as folows:

Example 10:

(S-4) '... it could be said that the speech and behavior of students during the learning process...' (PS-17) (M-4)

In example 10, the author used hedges in move 4 of abstarct. It can be seen by the use of lexicon 'could' as an expression of the tentativeness and posibility. This study has analyzed that postgraduate students have dominant usage of hedges. According to Zhang et al (2012) The possible reasons are might be the authors' lack of linguistic resources for expression of their own opinion and their relationship and interaction with their readers. It indicates that postgraduate students authors' should be improve the expressions of interactional metadiscourse.

In addition, this study also has analyzed the attitudinal stance. This study found only one the writer used attitudinal stance, this is example as below:

Example 11:

(S-4) '....School
characteristics (the socio-
cultural context) and
teachers' beliefs about ESP
were clearly seen as the most
influential factors on their
low levels of efficacy ...' (IA-
1) (M-3)

In the example above, the author used attitudinal stance as an expression of the author's judgment in move 3 of the abstract. It can be found by the use of lexicon 'clearly' in the sentence..

The last analyzed in the metadiscourse device is selfreference. The example for self reference words is as follow:

Example 12:

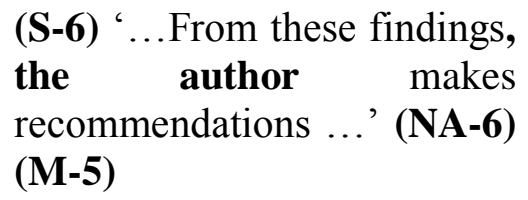

In example 12, the author using self- reference word to define the move 5 of the abstract. The selfreference words should be not use in 
the abstract, because self- reference is a subjective words. The examples of self- reference in this study such as 'the researcher', 'the author', 'I', and so on. According to Zhang et, al (2012) he suggest that using selfreference might be ascribed to the author's preoccupation with trying to sound as objective as possible by avoiding any reference to himself/ herself or his/ her own study. This finding indicate that just a view authors used self- reference.

\subsection{The Differences and} Similarities in Rhetorical Move and Linguistic Features in RA Abstracs Written by Three Groups of Authors.

By comparing the three groups of authors, this study found that move 1 reaches the smallest frequency and used by only 25 authors $(41,7 \%)$. Especially for the postgraduate students have the minimum frequency than national and international authors. The similarities of the structure move in this research have in the same highest frequency with three moves, they are move 2 , move 3 , and also move 4. Those moves such as obligatory in the English RA abstract written by three group of authors.

Second, the postgraduate students used past tense more dominant than present tense. Contrast with national and international authors, they are more dominant used present tense than past tense. In using hedges postgraduate students are highest frequency than national and international authors. The similarities of linguistic features also found in this study. First, in using voice three groups of author most dominant used active voice. Second, in type of sentence the three groups of authors most frequently used simple sentence in the abstract. The last, the three groups of authors have used selfreference in the minimum frequency.

In addition, the quality of abstracts are in using complete move (Move 1, Move 2, Move 3, Move 4, and Move 5). In the corpus of this study, the quality of abstracts based on complete moves are just a view. It means the authors (postgraduate students, national and international authors) should be used the five moves in the abstracts. This suggestion in line with Swales (2009) who suggest that the five moves in the abstracts. As linguistic features in the English RA abstracts using Voice (active and passive voice), Tenses (past and present tense), Sentence type (Simple and Complex sentence) are and option in the abstracts and minimize the usage of metadiscourse devices (Hedges, Attitudinal Stance, and SelfReference words).

\section{DISCUSSION}

The first objective of this research is to identify the common moves found in English RA abstract by three groups of authors in Applied Linguistics. The result showed that the dominant move of abstracts based on the corpus of the study are frequently with move 2 (Present research/ Purposes), move 3 (Methods/ Materials/ Subject/ Procedures), and move 4 (Results/ 
Finding). The majority of authors began their abstract with the move 2 (Present research/ Purposes). It indicate that for the postgraduate students, national authors, and international authors has three moves (move 2, move 3, and move 4) are obligatory and move 1 , move 5 are optional in their English abstracts. This results are in line with Can, et al (2016) who found that the majority of authors discussed the results, purpose, and methodology in their abstracts more than implications of the findings or background information. It might be caused the existence of various forms could be because there are no explicit standard rules for decision on moves for abstracts (Crookes: 1986).

There are some possiblity of English asbtracts in the corpus of the study. The technical guideline of writting this journal from JOALL (2017) implied that the abstract of research paper should contain title, purpose, method, and research finding. The statement in line with the result of postgraduate students' abstracts that majority of authors used three moves pattern. Author guidelines in the TEFLIN journal (2017) indicate that author guidelines for conceptual articles abstract maximal 100 words and for research based article maximal 200 word without any discription. IJES (2017) implied that the abstract no more than 150 word in length. Thus the corpus of the study have different structure moves in the English abstract. This finding show the similarities of Zang (2012), he found the most abstract in the dataset had three important moves Purposes,
Method, and Product but lack the Introduction and Conclusion moves as described in Hyland's (2000) IPMPrC Model.

Moreover, the qualified of abstracts should have five moves in abstracts such as move 1 (Background/ introduction/situation) move 2 (Present research/ Purposes), move 3 (Methods/ Materials/ Subject/ Procedures), move 4 (Results/ Finding) and move 5 (discussion/ conclusion/ implication/ recommendation) suggested by Swales (2009). This suggestion in line with Patridge in Safnil (2014), he suggested that a RA abstract should have five moves (main aim, specific objective, reason, process and results). It means important to include move 1 and move 5 to inform the readers in the practical benefit of the research finding.

The second results of this research is the common Linguistic Features found in English RA abstract in the corpus of the study. This study found that simple sentence become the highest frequently of the authors' used in English research article abstracts by three different groups of authors. Because of an abstract is a mini summary of the research, so the sentence represent of expression of the author's to make the reader easier find the key words of the research. The syntactical features has also voice, in this research the majority authors frequently used passive voice. This finding is in line with Zhang, et al (2012) who found that the total number of 20 abstracts the active voice used nearly twice as 
frequently in the abstracts as the passive voice.

Based on the results above, the authors are frequently used present tense in the English RA abstracts. Contrast to postgraduate students' dominance used past tense in their English RA abstracts. According to Swales (1990) mentioned that the use of tense (i.e. Present and past tense) are clear characteristics of abstract written in English 'present tense' is used to refer to the information available in the article and 'past tense' is used to stress the importance of the research results of findings. The next finding is hedges, attitudinal stance, and selfreference words. In this study the authors use hedges as expressions of tentativeness and possibility, but the highest frequently is postgraduate students'. While only a few of the national and international authors used hedges. On the other hand, the attitudinal stance was found in international authors. Self- reference words were used in a view English abstract written by three groups of author. The possible reason according to Zhang, et al (2012) it might be the author's lack of linguistic resources for the expression of their own opinions and their relationship and interaction with their readers. This result in line with Safnil (2014) the finding indicated that the use of interactional metadiscourse devices are very rare and dominated by hedges mostly found in Move 4 while the use of attitudinal stance of the writers and self- reference words are even rarer in the abstract.

The last objective of this research is the differences of rhetorical move and linguistic features written by three groups of authors. From the result and discussion above, it can be seen there are differences of rhetorical moves. First, by comparing the three groups of authors this study found that move 1 (Background/ introduction/ situation) have $25 \quad(41,7 \%)$. Especially for the postgraduate students have the minimum frequency than national and international authors.Second, postgraduate students dominantly used past tense than present tense. Contrast with national and international authors, they are most dominant used present tense than past tense. Third, in using hedges postgraduate students are highest frequency than national and international authors.

\section{CONCLUSION}

The data were obtained to answer the research question in analyzing the rhetorical structure and linguistic features by three groups of authors in Applied Linguistic. As the results of this study, it can be concluded as follows. The common moves used by postgraduate students, national and international authors found in the abstracts are move 2 (Present research/ Purposes), move 3 (Methods/ Materials/Subject/ Procedures), and move 4 (Results/ Finding). The common Linguistic Features used by postgraduate students, national authors, and international authors are active voice, present tense, simple sentence, and hedges. The postgraduate students used move 1 (Background/ introduction/ situation) fewer than national and international 
authors. They used dominantly past tense than present tense, and obtained the highest frequency in using hedges.

\subsection{Suggestion}

Based on the reseach finding that has been concluded above, some suggestions are proposed as follow. This study suggests that in writing RA abstracts a writer should adjust the commonly used rules the abstract especially in using 5 moves in the abstracts. For further research, they can propose in other institution of higher education from other disciplines. Due to the limited data of this study, the findings in the study need to be tested in larger scale studies.

\section{REFERENCES}

Atkinson. P, Coffey. A. (1996). Makin Sense of Qualitative Data:

Complementary Research Strategies. Michigan: Sage Publications.

Bathia. K. V. (1993). Analysing Genre: Language Use in Professional Settings. London: Longman.

Bhatia, Vijay. (1997). "Genre Analysis - Step by Step." Journal of Linguistics, no. 19: 207-40.

Cookes, G. (1986). Towards a Validated Analysis of a Scientific Text Structure. Applied Linguistics, 7 (1), 57-70.

Craswell, J, Plano. C. V. (2007) Designing and Conducting Mixed
Method Research. Thousand Oaks: Sage.

Can. S, Karabacak. E, Qin J. (2016). Structure of Moves in Research Article Abstracts in Applied Linguistics. MDPI. V 4, 23- 38.

Celik, S.S. \& Aydin, S. (2016). Wiki effect on English as a foreign language writing achievement. Global Journal of Foreign Language Teaching. 6(4), 218-227.

Golebiowski, Z. (2009). Prominent messages in Education and Applied Linguistics abstracts: How do authors appeal to their prospective readers? Journal of Pragmatics, 41(4), 753-769.

Hyland. K., Tse, P. (2005) Evaluative that constructions: signaling stance in research abstract. Fuction of Language, 12 (1), 39-63.

Hyland, K. (2000). Disciplinary Discourse: Social Interactions in Academic Writing. London: Longman.

Kusnadi. T and Bharati. D. (2012). Developing an english instructional material for bridging course program. English Education Journal, 2(2), 207-211.

Pho, P. D (2010). Linguistic realizations of rhetorical structure a corpus- based study of research article abstract and introducion in applied linguistics and educational technology.

Ren. H., Y. Li (2011). A comparison 
study on the rhetorical moves of abstract in published research articles and master foreign language thesis, English Language Teaching, v. 4(1), 162- 166.

Safnil (2014) The Discourse Structure and Linguistic Features of Research Article Abstracts in English by Indonesian Academic. Bengkulu: Asian ESP Journal Vol.10 (Issue 2) (pp:191-224).

San. L. Y, Tan H. (2012). A comparative study of the rhetorical moves in abstracts of published research articles and students' term papers in the field of computer and communication systems engine. International Journal of Applied Linguistics And English Literature, v 1(7) 40-50.

Saewae. S, Tangkiengsirisin. S. (2014). Rhetorical Variation across Research Article Abstracts in Environmental Science and Applied Linguistics. English Language Teching. V 7 (8) 81-93.

Suntara. W, Usaha S. Research article abstracts in two related disciplines: rhetorical variation between linguistics and applied linguistics. English Language Teaching, v 6 (2) 84-99.

Swales, J. M (2004). Research analysis: English in Academic and Research Settings. Cambridge: Cambridge University Press
Swales. J. M, C. B Feak. (2009) Abstract and The Writing of Abstracts. United States: Michigan Press.

Tseng , F. (2011). Analysis of move structure and verb tense of research article abstract in Applied Linguistics journal's, International Journal of English Linguistics, 1(2), 27- 39

Yik San, Lam, and Helen Tan. (2012). "A Comparative Study of the Rhetorical Moves in Abstracts of Published Research Articles and Students'Term Papers in the Field of Computer and Communication Systems Engineering." International Journal of Applied Linguistics \& English Literature 1 (7): 4050. doi:10.7575/ijalel.v.1n.7p.40.

Zhan, B, Q. B. T. Thuc and I , Pramoolsook (2012). Move and linguistic realizations: English research article abstract by Vietnamese argicultural researchers, The Asean ESP Journal ,v. 8(3), 126- 149. 